\title{
Retraction Note to: Preliminary comparing the toxicities of the hybrid crylAcs fused with different heterogenous genes provided guidance for the fusion expression of Cry proteins
}

Ying Tang $\cdot$ Jinying Tong $\cdot$ Yunlei Zhang $\cdot$

Lei Wang • Shengbiao Hu $\cdot$ Wenping Li •

Yuan Lv

Published online: 24 January 2015

(C) Springer Science+Business Media Dordrecht 2015

\section{Retraction Note to: World J Microbiol Biotechnol}

(2012) 28:397-400

DOI 10.1007/s11274-011-0825-0

The authors have decided to retract their article entitled "Preliminary comparing the toxicities of the hybrid crylAcs fused with different heterogenous genes provided guidance for the fusion expression of Cry proteins" in World J Microbiol Biotechnol (2012 Jan; 28(1):397-400).
Upon executing further experiments, it has been found that neither of the two fused hybrid Cry1Ac proteins had a statistically significant increase in the toxicity in comparison with Cry1Ac protein. The difference between the toxicities of the two hybrid Cry1Ac proteins was also statistically insignificant.

The online version of the original article can be found under doi: 10.1007/s11274-011-0825-0.

Y. Tang $\cdot$ Y. Zhang $\cdot$ S. Hu $\cdot$ W. Li $\cdot$ Y. Lv

College of Life Science, Hunan Provincial Key Laboratory of Microbial Molecular Biology-State Key Laboratory Breeding Base of Microbial Molecular Biology, Hunan Normal

University, Changsha 410081, China

J. Tong · L. Wang · Y. Lv ( $₫)$

Department of Epidemiology, College of Medicine,

Hunan Normal University, Changsha 410081, China

e-mail: Ly598598@126.com 